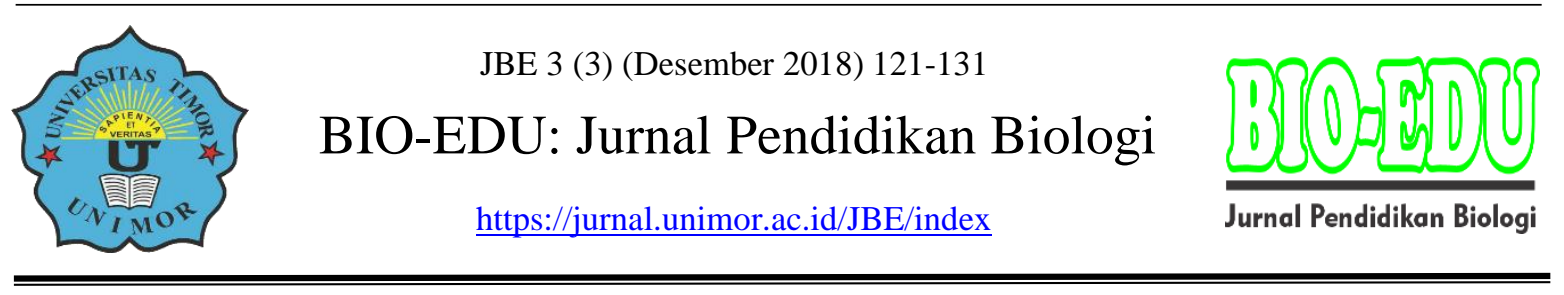

\title{
Uji Kualitas Air Sumur di Kefamenanu Ditinjau Dari Segi Fisik Kimia dan Mikrobiologi
}

\author{
Yantonius Seran Taek ${ }^{1}$ Sefrinus M.D. Kolo ${ }^{2}$ Ludgardis Ledheng $^{3}$ \\ ${ }^{1,2,3}$ Fakultas Ilmu Pendidikan, Universitas Timor, Kefamenanu, TTU - NTT, 85613, Indonesia \\ Email: yantoniusserantaek@gmail.com
}

DOI: https://doi.org/10.32938/jbe.v3i3.687

\begin{abstract}
Abstrak
Air merupakan komponen lingkungan yang penting bagi kehidupan di muka bumi. Oleh karena itu kebutuhan akan air harus diperhatikan baik kualitas maupun kuantitasnya, tetapi realita yang terjadi banyak masyarakat menggunakan air yang kualitasnya dibawah standar baku mutu kualitas air menurut Peraturan Menteri Kesehatan Republik Indonesia Nomor 492Menkes/Per/IV/2010. Penelitian ini bertujuanuntuk mengetahui karateristik fisik, kimia dan mikrobiologi serta untuk mengetahui nilai konsentrasi parameter fisik, kimia dan mikrobiologi air sumur di Kefamenanu sama dengan nilai ambang batas yang ditetapkan permenkes nomor 492. Teknik pengambilan sampel diambil secara acak pada empat lokasi yaitu air sumur area Rumah Sakit, Tulip, Maubeli dan Sasi. Berdasarkan hasil analisis laboratorium Dinas Kesehatan Kefamenanu diperoleh hasil parameter fisik yang meliputi suhu, bau, rasa dan warna keempat air sumur tersebut memenuhi syarat baku mutu kualitas air bersih. Parameter kimia meliputi besi, mangan, timbal dan $\mathrm{pH}$ diperoleh hasil air sumur area rumah sakit besi(Fe) $=0,05 \mathrm{mg} / \mathrm{l}$, mangan $(\mathrm{Mn})=0,4 \mathrm{mg} / \mathrm{l}$, timbal $(\mathrm{Pb})=0 \mathrm{mg} / \mathrm{l}$ dan $\mathrm{pH}=8$, air sumur area Tulip besi $=0,2 \mathrm{mg} / \mathrm{l}$, mangan $=0,7 \mathrm{mg} / \mathrm{l}$, timbal= 0 $\mathrm{mg} / \mathrm{l}$ dan $\mathrm{pH}=8$, air sumur areaMaubeli besi $=0,5 \mathrm{mg} / \mathrm{l}$, mangan $=0,1 \mathrm{mg} / \mathrm{l}$, timbal $=0 \mathrm{mg} / \mathrm{l}$ dan $\mathrm{pH}=8$ serta pada air sumur area Sasi besi $=0,5 \mathrm{mg} / \mathrm{l}$, mangan $=0 \mathrm{mg} / \mathrm{l}$, timbal $=0 \mathrm{mg} / \mathrm{l}$ dan $\mathrm{pH}=8$ dan parameter mikrobiologi (coliform) di area rumah sakit $=1898$, area tulip $=438$, area Maubeli $=33$ dan untuk area Sasi= 13 dan bakteri $E$. coli area rumah sakit $=1898$, area tulip=38, area Maubeli=26 dan area $S a s i=13$ dapat disimpulkan bahwa air sumur area rumah sakit dan air sumur area tulip tidak memenuhi standar baku mutu kualitas air bersih sesuai dengan peraturan Permenkes No: 492/Menkes/Per /IV/2010.
\end{abstract}

Kata Kunci: Air; Parameter Fisika; Parameter Kimia; Parameter Mikrobiologi.

\section{PENDAHULUAN}

Air merupakan kebutuhan dasar bagi kehidupan semakin naik jumlah penduduk maka semakin naik pula laju pertumbuhan dan laju pemanfaatan sumber-sumber air. Pengotoran air akan bertambah cepat sesuai dengan cepatnya pertumbuhan jumlah penduduk oleh karena itu air bersih menjadi semakin langka sehingga pengelolaan sumber daya air menjadi sangat penting baik dalam pemanfaatan maupun dalam pengelolaan kualitas(Astuti, 2015).

Masalah penyediaan air bersih ini menjadi salah satu prioritas dalam perbaikan derajat kesehatan masyarakat. Keberadaan air sangat vital dibutuhkan oleh makhluk hidup karena kehidupan di muka bumi ini hanya dapat berlangsung dengan keberadaan air. Seiring meningkatnya kepadatan penduduk dan pesatnya pembangunan maka kebutuhan air pun semakin meningkat. Dituntut ketersediaan air sehat yang meliputi pengawasan dan penetapan kualitas air untuk berbagai kebutuhan dan kehidupan manusia yang bertujuan untuk menjamin tercapainya air 
minum maupun air bersih yang memenuhi syarat kesehatan bagi seluruh lapisan masyarakat. Banyak penduduk yang terpaksa memanfaatkan air yang kurang bagus kualitasnya untuk keperluan rumah tangga akibatnya banyak masyarakat Kefamenanu yang menderita berbagai penyakit contohnya diare, kulit dan lain-lain.

Berdasarkan data mengenai kualitas air sumur di dekat pembuangan akhir sampah di Piyungan diketahui bahwa pengelolaan sampah di Tempat Penampungan Akhir (TPA) sangat berpengaruh terhadap kualitas air sumur masyarakat di sekitarnya, khususnya pada parameter mikrobiologi yaitu coliform dan E.coli. Dari analisis kandungan air sumur warga yang dekat tempat sampah, diketahui bahwa secara uji kualitas bakteriologi dari 25 sampel hanya 4 sampel air sumur yang memenuhi syarat baku mutu kualitas air bersih sesuai dengan Peraturan Menteri Kesehatan Republik Indonesia Nomor 492 /Menkes/ Per / IV/2010(Astuti, 2015).

Berdasarkan pendapat tersebut masyarakat di kota Kefamenanu menggunakan berbagai jenis air untuk kebutuhan hidupnya, salah satunya menggunakan air sumur sebagai sumber air minum. Oleh karena itu, sangat penting untuk dilakukan suatu penelitian yang bertujuan untuk mengetahui kualitas air sumur yang digunakan masyarakat di Kefamenanu apakah layak digunakan atau tidak layak digunakan oleh masyarakat yang ada di Kefamenanu.

Bertolak dari beberapa data-data tersebut maka peneliti tertarik untuk melakukan suatu penelitian mengenai Uji Kualitas Air Sumur Di Kefamenanu Ditinjau Dari Segi Fisik, Kimia Dan Mikrobiologi yang meliputi tiga parameter yang diukur yaitu parameter fisik meliputi: bau, rasa, warna dan suhu, pengukuran parameter kimia meliputi: besi (Fe), Mangan (Mn), pH, dan Timbal $(\mathrm{Pb})$. Sedangkan pengukuran parameter mikrobiologi meliputi: Total coliform dan E. coli dengan metode MPN (Most Probable Number).

\section{METODE}

\section{Waktu dan Tempat}

Penelitian ini telah dilaksanakan pada bulan: Juli 2017 di Laboratorium Dinas Kesehatan Kefamenanu Kabupaten Timor Tengah Utara (TTU).

\section{Alat dan Bahan}

Tabel 1 Alat dan Bahan Penelitian

\begin{tabular}{|c|c|c|}
\hline No & Alat & Kegunaan \\
\hline 1 & $\begin{array}{l}\text { Botol } \\
\text { sampel }\end{array}$ & $\begin{array}{l}\text { Digunakan sebagai tempat } \\
\text { penyimpanan sampel air. }\end{array}$ \\
\hline 2 & Inqubator & $\begin{array}{lr}\text { Digunakan untuk } \\
\text { penyeraman sampel yang } \\
\text { telah siap untuk } \\
\text { dieramkan. }\end{array}$ \\
\hline 3 & Autoclave & $\begin{array}{lr}\text { Digunakan } & \text { untuk } \\
\text { menstrilkan reagen yang } \\
\text { akan digunakan dalam } \\
\text { penelitian. }\end{array}$ \\
\hline 4 & $\begin{array}{l}\text { Tabung } \\
\text { durhan }\end{array}$ & $\begin{array}{l}\text { Digunakan sebagai wadah } \\
\text { sampel yang akan diteliti. }\end{array}$ \\
\hline 5 & $\begin{array}{l}\text { Batang } \\
\text { pengaduk }\end{array}$ & $\begin{array}{lr}\text { Digunakan } & \text { untuk } \\
\text { mengaduk } & \text { campuran }\end{array}$ \\
\hline
\end{tabular}




\begin{tabular}{|c|c|c|}
\hline No & Alat & Kegunaan \\
\hline & & $\begin{array}{l}\text { bahan-bahan yang dipakai } \\
\text { dalam penelitian. }\end{array}$ \\
\hline 6 & Pipet & $\begin{array}{lr}\text { Digunakan } & \text { untuk } \\
\text { mengambil media yang } \\
\text { telah dibuat atau } \\
\text { diencerkan terbuat dari } \\
\text { plastik dan kapasitasnya } 5 \\
\text { atau 10cc. }\end{array}$ \\
\hline 7 & Gelas ukur & $\begin{array}{l}\text { Digunakan nutuk } \\
\text { mengukur volume laruan } \\
\text { yang akan dipakai. }\end{array}$ \\
\hline 8 & Kawat ose & $\begin{array}{l}\text { Digunakan untuk } \\
\text { mengambil spesimen hasil } \\
\text { uji sampel. }\end{array}$ \\
\hline 9 & Oven & $\begin{array}{l}\text { Digunakan } \\
\text { mensterilkan antuk } \\
\text { yang digunakan untuk } \\
\text { penelitian. }\end{array}$ \\
\hline 10 & $\begin{array}{l}\text { Timbangan } \\
\text { analitik }\end{array}$ & $\begin{array}{l}\text { Digunakan untuk } \\
\text { menimbang bahan-bahan } \\
\text { yang akan dipakai dalam } \\
\text { penelitian. }\end{array}$ \\
\hline 11 & $\mathrm{pH}$ meter & $\begin{array}{l}\text { Digunakan untuk } \\
\text { mengukur pH sampel. }\end{array}$ \\
\hline 12 & Termometer & $\begin{array}{lr}\text { Digunakan } & \text { untuk } \\
\text { mengukur suhu sampel } \\
\text { air. }\end{array}$ \\
\hline 13 & $\begin{array}{l}\text { Pemanas } \\
\text { listrik }\end{array}$ & $\begin{array}{l}\text { Digunakan } \\
\text { melarutkan reagen. }\end{array}$ \\
\hline 14 & $\begin{array}{l}\text { Beaker glass } \\
250 \mathrm{ml}\end{array}$ & $\begin{array}{l}\text { Digunakan sebagai wadah } \\
\text { sampel air yang akan } \\
\text { diperiksa. }\end{array}$ \\
\hline & Bunsen & $\begin{array}{l}\text { Digunakan untuk } \\
\text { memanaskan mulut botol } \\
\text { sampel. }\end{array}$ \\
\hline
\end{tabular}

Sedangkan bahan yang digunakan dalam penelitian ini adalah :

1) Contoh air / sampel air

2) Aquades steril untuk melarutkan BGLB dan LB

3) Brilliant Green Laktosa Broth (BGLB) sebanyak 40gr dilarutkan dalam 1 liter aquades

4) Laktose Broth (LB) sebanyak 13gr dilarutkan dalam 500ml aquades

5) Korek api

6) Kapas untuk menutup mulut tabung

7) Alkohol 70\% 


\section{Teknik Pengumpulan Data}

Teknik pengumpulan data dilakukan dengan menggunakan data primer. Data ini diperoleh dari hasil observasi sumur gali pada empat titik di Kefamenanu Kabupaten Timor Tengah Utara (TTU) dan hasil analisis di laboratorium.

\section{Prosedur Penelitian}

Jenis penelitian ini adalah penelitian observasional yaitu peneliti melakukan observasi terhadap kualitas fisik, kimia dan mikrobiologi air sumur gali yang terdapat di Kota Kefamenanu. Setelah dilakukan observasiselanjutnya dianalisis di laboratorium terhadap kualitas fisik, kimia dan mikrobiologi kemudian hasilnya akan didekripsikan. Berikut ini tahap-tahap yang dilakukan dalam penelitian:

a. Parameter Fisika

- Pengukuran Warna

Dilihat secara teliti warna air sumur dan dicacat hasilnya

- Prosedur Pengukuran Bau

Diambil sampel air sumur dan menaruhnya disuatu tempat yang bersih misalnya cawan lalu diangin-angin kea rah hidung dan dicatat hasilnya.

- Prosedur Pengukuran Rasa

Diambil sampel air sumur sebanyak 1 tetes, merasakanya dengan lidah, kemudian mengeluarkannya kembali dan dicatat hasilnya. Parameter ini erat hubungannya dengan pengujian parameter warna dan bau sehingga seringkali pada pelaksanaannya digabungkan. Rasa air dalam kondisi baik berasa hambar, bila suatu perairan sudah berwarna kurang baik atau bau yang kurang sedap secara otomatis akan mempunyai rasa yang kurang enak.

b. Parameter Kimia

- Besi/Fe

Diisikan sampel air sumur $10 \mathrm{ml}$ kedalam tabung uji $10 \mathrm{ml}$, ditambahkan satu tablet reagen iron LR,dihancurkan dan aduk hingga larut, tunggu selama 1 menit untuk mendapatkan perubahan warna. Dinyalakan photometer 7500, dan pilih (Phot 18) kemudian tekan tombol (OK) jika pada layar LCD photometer 7500 muncul dialog (insert Blank), dimasukan blangko yang berwarna jernih, tetapi sudah dimasukan dalam kit, kemudian diletakan pada tube photometer 7500 untuk melakukan kalibrasi, diletakan sampel yang tercampur dengan reagen tersebut kedalam tube photometer 7500, jika telah diletakan maka tekan tombol (OK) untuk memulai pembacaanya, layar LCD photometer akan menampilkan hasilnya $\mathrm{mg} / \mathrm{l} \mathrm{Fe}$ lalu dicatat hasil untuk mendapatkan data pengukuran.

- Mangan/Mn

Ion mangan dalam suasana asam panas dan dengan larutan ini dioksidasi oleh persulfatmenjadi senyawa mangan yang berwarna ungu kemerahan. Langkahnya:

Diisikan sampel air sumur $10 \mathrm{ml}$ kedalam tabung uji $10 \mathrm{ml}$, ditambahkan satu tablet reagen manganese nomor 1, dihancurkan dan aduk hingga larut. Ditambahkan lagi reagenese nomor 2, dihancurkan aduk hingga merata, tunggu selama 20 menit untuk mendapatkan perubahan warna. Dinyalakan photometer 7500,dan pilih (Phot 20) kemudian tekan tombol (OK) jika pada layar LCD photometer 7500 muncul dialog (insert Blank), dimasukan blangko yang berwarna jernih, tetapi sudah dimasukan kit,kemudian letakan pada tube photometer 7500 untuk melakukan kalibrasi, letakan sampel yang tercampur dengan reagen tersebut kedalam tube photometer 7500 , 
jika telah diletakan maka tekan tombol (OK) untuk memulai pembacaanya, layar LCD photometer akan menampilkan hasilnya mg/l Mn, lalu dicatat hasil untuk mendapatkan data pengukuran.

- Pemeriksaan Timbal $(\mathrm{Pb})$

Disiapkan sampel air sumur, dimasukan $5 \mathrm{ml}$ sampel air sumur kedalam tabung uji, ditambahkan tiga tetes reagen $\mathrm{Pb} 1$ lalu diaduk hingga rata, masukan alat tes $\mathrm{Pb}$ lalu didiamkan selama dua menit kemudian dicatat hasil.

- Pemeriksaan pH

Disiapkan bahan dan alat, dituangkan air sampel kedalam beaker glass $50 \mathrm{ml}$ secukupnya, dicelupkan kertas lakmus pada air sampel lalu angkat kembali lalu dicocokan dengan warna yang sudah ada pada kertas label.

c. Parameter Mikrobiologi

Cara kerja pada saat pengambilan sampel di lapangan/lokasi penelitian dilakukan pada sore hari, sebelum melakukan pengambilan sampelperlu disiapkan terlebih dahulu alat dan bahan yang diperlukan seperti botol sampel, alat timba, tali, alkohol 70\%, kertas label, pemantik dan lampu spritus. Botol sampel yang akan digunakan lebih dulu disterilisasidi laboratorium.Proses pengambilan sampel air sumur gali dilakukan dengan prosedur sebagai berikut:

Dipersiapkan lembar observasi sesuai dengan nomor sumur, tangan dicuci dengan alkohol $70 \%$ diikat tali pada botol timba yang sudah disterilkan, diturunkan botol sampel ke dasar sumur minimal $15 \mathrm{~cm}$ dari dasar air dan menariknya keatas difiksasi mulut botol sampel dengan spiritus selama 30 detik secara bersamaan difiksasi mulut botol timba dan botol sampel dengan spritus kemudian memindahkan air dari botol timba kedalam botol sampel, ditutup rapat botol sampel diberi label pada botol sampel lalu dimasukkan dan mengatur posisi botol sampel dengan rapi agar tidak miring.

d. Cara kerja di laboratorium

Cara kerja untuk proses sterilisasi botol sampel adalah sebagai berikut: disiapkan botol sampel untuk pengambilan sampel air sumur digunakan botol-botol yang ditutup dengan sempurna, dibersihkan botol dan membilasnya sebanyak 2 kali dengan air destilasi dibungkus leher botol dengan aluminium foil. Disterilkannya selama 60 menit pada suhu $180^{\circ} \mathrm{C}$ dalam oven, tandai botol dengan memberi catatan tanggal sterilisasinya lalu menyimpan botol-botol yang telah siap digunakan pada tempat yang bersih.

Selanjutnya untuk melakukan pengujian kualitas mikrobiologi air sumur gali maka perlu disiapkan terlebih dahulu alat dan bahan yang diperlukan.

Alat yang digunakan: tabung, rak tabung, pipet, jarum ose, incubator, autoclave dan lampu spritus.

Bahan yang diperlukan: sampel air sumur gali di Kota Kefamenanu, media LB (Lactose Broth), Media BGLB, aquades steril, alkohol $70 \%$ dan kapas steril. Untuk menguji kandungan mikrobiologi air sumur gali, maka ada dua tes yang dilakukan yakni tes perkiraan dan tes penegasan dengan menggunakan metode perbandingan 3:3:3.

Cara kerja yaitu sebagai berikut:

a. Pembuatan media perkiraan awal atau LB (Lactose Broth)

Ditimbang media LB pekat (LBDS) 6,5 gram untuk aquades $250 \mathrm{ml}$, dan media LB encer (LBSS) 13 gram untuk aquades $1000 \mathrm{ml}$ dipanaskan media tersebut diatas pemanas air hingga larut, $\mathrm{pH}$ diukur hingga normal (6,5-8,5)disiapkan tabung sebanyak 150 buah, diisi media pekat kedalam tabung masing-masing 5ml/tabung dan untuk media encer masing-masing 10 $\mathrm{ml} /$ tabung ditutup tabung dan disterilkannya didalam autoclave dengan suhu $121^{\circ} \mathrm{C}$ selama 15 menit. 
b. Pembuatan media penegasan atau BGLBB (Brilliant Green Lactose Bile Broth)

Ditimbang media 80 gram dengan aquades 2 liter lalu dipanaskan diatas pemanas air hingga larut, $\mathrm{pH}$ diatur hingga normal $(7,2)$ disiapkan tabung sebanyak 40 buah, diisi media kedalam tabung ditutup tabung dan disterilkannya didalam autoclave dalam suhu $121^{\circ} \mathrm{C}$ selama 15 menit.

c. Pemeriksan sampel dengan metode 3:3:3

- Tes Perkiraan(Azwar Ali, 2013)

Disiapkan alat dan bahan yang digunakan yaitu: tabung, rak tabung, pipet, lampu spritus, incubator, aquades, diletakkan media LB 9 tabung kedalam rak tabung (3:3:3) dimasukkan sampel air sumur gali $10 \mathrm{ml}$ pada 3 tabung yang berisi LB $5 \mathrm{ml}, 1 \mathrm{ml}$ pada 3 tabung yang berisi LB $10 \mathrm{ml}$ dan 0,1 pada 3 tabung lagi yang berisi LB10 ml, tabung ditutup menggunakan kapas dimasukkannya kedalam inkubator selama 2 x 24 jam untuk pembiakan bakteri dalam suhu $37^{\circ} \mathrm{C}$ dibaca hasilnya, dinyatakan positif $E$. Coli apabila terdapat gelembung pada tabung.

- Tes Penegasan

Media yang terdeteksi positif di tes kembali menggunakan tes penegasan/ BGLB dengan cara mengangkat gelembung tersebut dengan menggunakan ose yang telah dipanaskan kedalam tabung yang berisi media BGLB $10 \mathrm{ml}$ dimasukkan kedalam inkubator selama 2 x 24 jam pada suhu yang berbeda yaitu $37^{\circ} \mathrm{C}$ untuk coliform dan $44^{\circ} \mathrm{C}$ untuk E. Coli lalu dibaca hasilnya dinyatakan positif $E$. coli apabila terdapat gelembung pada tabung.

\section{Analisis Data}

Analisis datanya melakukan perbandingan antara hasil penelitian dengan data yang sudah di tetapkan oleh Peraturan Menteri Kesehatan Republik Indonesia sesuai dengan standar.

\section{HASIL DAN PEMBAHASAN}

\section{Hasil}

Hasil penelitian air sumur dari 4 titik yaitu area Rumah Sakit, area Tulip,Maubeli dan area Sasi. Tiga parameter yang dianalisis dapat dilihat pada tabel berikut:

a. Pemeriksaan Parameter fisika

Tabel 1 Hasil Analisis Parameter Fisika, Air Sumur pada empat titik di Kefamenanu.

\begin{tabular}{|c|c|c|c|c|c|}
\hline \multirow[t]{2}{*}{ Parameter } & \multirow{2}{*}{$\begin{array}{c}\text { Standar } \\
\text { baku } \\
\text { mutu }\end{array}$} & \multicolumn{4}{|c|}{ Hasil Analisis Sumur } \\
\hline & & $\begin{array}{c}\text { Rumah } \\
\text { sakit }\end{array}$ & Tulip & Maubeli & Sasi \\
\hline Suhu & $\begin{array}{c}\text { Suhu } \\
\text { udara } \pm 3\end{array}$ & $27^{0} \mathrm{C}$ & $27^{0} \mathrm{C}$ & $26^{0} \mathrm{C}$ & $\begin{array}{l}25 \\
{ }^{0} \mathrm{C} \\
\end{array}$ \\
\hline $\mathrm{Bau}$ & $\begin{array}{c}\text { Tidak } \\
\text { berbau }\end{array}$ & $\begin{array}{l}\text { Tidak } \\
\text { berbau }\end{array}$ & $\begin{array}{l}\text { Tidak } \\
\text { berbau }\end{array}$ & $\begin{array}{l}\text { Tidak } \\
\text { berbau }\end{array}$ & $\begin{array}{c}\text { Tida } \\
\text { k } \\
\text { berb } \\
\text { au }\end{array}$ \\
\hline Rasa & $\begin{array}{l}\text { Tidak } \\
\text { berasa }\end{array}$ & $\begin{array}{l}\text { Tidak } \\
\text { berasa }\end{array}$ & $\begin{array}{l}\text { Tidak } \\
\text { berasa }\end{array}$ & $\begin{array}{l}\text { Tidak } \\
\text { berasa }\end{array}$ & $\begin{array}{c}\text { Tida } \\
\mathrm{k} \\
\text { bera } \\
\text { sa }\end{array}$ \\
\hline
\end{tabular}




\begin{tabular}{cccccc}
\hline Warna & $\begin{array}{c}\text { Tidak } \\
\text { berwarna }\end{array}$ & $\begin{array}{c}\text { Tidak } \\
\text { berwarn }\end{array}$ & $\begin{array}{c}\text { Tidak } \\
\text { berwar }\end{array}$ & $\begin{array}{c}\text { Tidak } \\
\text { berwarn }\end{array}$ & $\begin{array}{c}\text { Tida } \\
\mathrm{k} \\
\text { berw } \\
\end{array}$ \\
& $\mathrm{a}$ & na & $\mathrm{a}$ & \begin{tabular}{c} 
arna \\
\hline
\end{tabular} \\
\hline
\end{tabular}

b. Pemeriksaan Parameter Kimia

Tabel 2 Hasil Analisis Parameter kimia, Air Sumur pada empat titik di Kefamenanu.

\begin{tabular}{cccccc}
\hline Parameter & $\begin{array}{c}\text { Standar } \\
\text { baku } \\
\end{array}$ & \multicolumn{4}{c}{ Hasil Analisis Sumur } \\
\cline { 3 - 6 } & Rutu & $\begin{array}{c}\text { Rumah } \\
\text { sakit }\end{array}$ & Tulip & Maubeli & Sasi \\
\hline Besi & 0,3 & 0,05 & 0,2 & $0.05 \mathrm{mg} / \mathrm{l}$ & 0.05 \\
& $\mathrm{mg} / \mathrm{l}$ & $\mathrm{mg} / \mathrm{l}$ & $\mathrm{mg} / \mathrm{l}$ & & $\mathrm{mg} / \mathrm{l}$ \\
\hline Mangan & 0,4 & 0,4 & 0,7 & $0,1 \mathrm{mg} / \mathrm{l}$ & $\begin{array}{c}0 \\
\mathrm{mg} / \mathrm{l}\end{array}$ \\
& $\mathrm{mg} / \mathrm{l}$ & $\mathrm{mg} / \mathrm{l}$ & $\mathrm{mg} / \mathrm{l}$ & & \\
\hline Timbal & 0,01 & $0 \mathrm{mg} / \mathrm{l}$ & $0 \mathrm{mg} / \mathrm{l}$ & $0 \mathrm{mg} / \mathrm{l}$ & $\begin{array}{c}0 \\
\mathrm{mg} / \mathrm{l}\end{array}$ \\
\hline $\mathrm{pH}$ & $6,5-8,5$ & 8 & 8 & 8 & 8 \\
\hline
\end{tabular}

c. Pemeriksaan Parameter Mikrobiologi

Tabel 3 Hasil Analisis Parameter Mikrobiologi, Air Sumur dari empat titik di Kefamenanu.

\begin{tabular}{cccccc}
\hline Parameter & $\begin{array}{c}\text { Standar } \\
\text { baku } \\
\text { mutu }\end{array}$ & \multicolumn{4}{c}{ Hasil Analisis Sumur } \\
\cline { 3 - 6 } & $\begin{array}{c}\text { Rumah } \\
\text { sakit }\end{array}$ & Tulip & Maubeli & Sasi \\
\hline Coliform & 50 & $>1898$ & 438 & 33 & 13 \\
\hline E. coli & 50 & $>1898$ & 38 & 26 & 13 \\
\hline
\end{tabular}

\section{Pembahasan}

\section{a. Hasil Uji Kualitas Air secara Fisika}

Ditinjau dari segi fisika yang meliputi suhu, bau, rasa dan warna pada tabel 1 sebagai berikut:

1. Suhu

Berdasarkan uji suhu keempat air sumur sebagai air bersih yang telah dilakukan di Laboratorium Kesehatan Kefamenanu Kabupaten Timor Tengah Utara (TTU)hasil uji suhu keempat air sumur adalah air sumur area rumah sakit $27^{\circ} \mathrm{C}$, area Tulip $27^{\circ} \mathrm{C}$, Maubeli suhunya $26^{\circ} \mathrm{C}$ dan Sasi suhunya $25^{\circ} \mathrm{C}$ (Normal)dan layak sesuai baku mutu dari Permenkes No:492/Menkes/Per/ IV/2010 sebesar suhu udara. Air yang baik harus memiliki suhu sama dengan suhu udara $(20-60)^{0} \mathrm{C}$. Air yang secara mencolok mempunyai suhu di atas atau di bawah suhu udara berarti mengandung zat-zat tertentu misalnya fenol yang terlarut didalam air cukup banyak atau sedang terjadi proses tertentu (proses dekomposisi bahan organik oleh mikroorganisme yang menghasilkan energi) yang mengeluarkan atau menyerap energi dalam air. 


\section{Bau}

Pengujian bau keempat air sumur sebagai air bersih yang telah dilakukan di Laboratorium Kesehatan Kefamenanu Kabupaten Timor Tengah Utara (TTU)hasil bau air keempat air sumur adalah tidak berbau (Normal) dan layak sesuai baku mutu dari Permenkes No: 492/Menkes/Per /IV/2010. Air yang baik memiliki ciri tidak berbau bila dicium dari jauh maupun dari dekat. Air yang berbau busuk mengandung bahan-bahan organik yang sedang mengalami dekomposisi oleh mikrorganisme air (Slamet, 2003).

3. Rasa

Pengujian rasa keempat air sumur sebagai air bersih yang telah dilakukan di Laboratorium Kesehatan Kefamenanu Kabupaten Timor Tengah Utara (TTU)hasil rasa keempat air sumur adalah tidak berasa (Normal) dan layak sesuai baku mutu dari Permenkes No: 492/Menkes/Per /IV/2010. Secara fisika, air bisa dirasakan oleh lidah. Air yang terasa asam, manis, pahit, atau asin menunjukkan bahwa kualitas air tersebut tidak baik. Rasa asin disebabkan adanya garam-garam tertentu yang larut dalam air sedangkan rasa asam diakibatkan adanya asam organik maupun asam anorganik.

4. Warna

Pengujian warna keempat air sumur sebagai air bersih yang telah dilakukan di Laboratorium Kesehatan Kefamenanu Kabupaten Timor Tengah Utara(TTU) hasil warna keempat air sumur tersebut tidak berwarna dan layak digunakan.

\section{b. Hasil Uji Kualitas Air secara Kimia}

Ditinjau dari segi kimia meliputi: Besi (Fe), Mangan (Mg), Timbal (Pb) dan pH pada tabel 7 sebagai berikut:

1) Besi (Fe)

Pengujian kandungan Besi $(\mathrm{Fe})$ pada keempat air sumur sebagai air bersih yang dilakukan di Laboratorium Kesehatan Kefamenanu Kabupaten Timor Tengah Utara (TTU) hasil Besi (Fe) dalam keempat air sumur adalah area rumah sakit $0,05 \mathrm{mg} / \mathrm{l}$, area tulip $0,2 \mathrm{mg} / \mathrm{l}$, Maubeli kandungan besi $0,05 \mathrm{mg} / \mathrm{l}$ dan Sasi sebesar $0,05 \mathrm{mg} / \mathrm{l}$ (Normal) layak sesuai baku mutu dari Permenkes No: 492/Menkes/Per / IV / 2010 adalah 3,0 Mg/l.

2) Mangan $(\mathrm{Mn})$

Pengujian kadar mangan (Mn) pada keempat air sumur sebagai air bersih yang dilakukan di Laboratorium Kesehatan Kefamenanu Kabupaten Timor Tengah Utara (TTU) hasil mangan (Mn) dalam keempat air sumur adalah area rumah sakit 0,4 mg/l, area tulip 0,7 mg/l, Maubeli kandungan mangannya $0,1 \mathrm{mg} / \mathrm{l}$ dan Sasi sebesar $0 \mathrm{mg} / \mathrm{l}$. Dari keempat titik hanya terdapat satu sumur yang tidak memenuhi standar yaitu air sumur Tulip sebesar 0,7 mg/l, Rumah Sakit 0,4 mg/l, sumur rumah sakit masih memenuhi standar baku mutu air bersih sebab standar baku mutu air yang di tetapkan sebesar 0,4 mg/l. Air Sumur Maubelisebesar 0,1mg/l dan sumur Sasi tidak terdapat logam mangan. Kandungan mangan $(\mathrm{Mn})$ dalam air sumur akan menimbulkan masalah warna seperti ungu atau hitam (Soemirat J, 2003).

3) Timbal $(\mathrm{Pb})$

Pengujian kadar Timbal $(\mathrm{Pb})$ pada keempat air sumur sebagai air bersih yang dilakukan di Laboratorium Kesehatan Kefamenanu Kabupaten Timor Tengah Utara (TTU) hasil uji timbal (Pb) dari air sumur adalah $0,00 \mathrm{mg} / \mathrm{l}$ (Normal) dan layak sesuai nilai baku mutu dari Permenkes No: 492/ Menkes / Per /IV/2010 adalah 0,01 mg/l.

4) $\mathrm{pH}$ 
Pengujian $\mathrm{pH}$ pada keempat air sumur sebagai air bersih yang dilakukan di Laboratorium Kesehatan Kefamenanu Kabupaten Timor Tengah Utara (TTU) hasil pH dalam keempat air sumur adalah 8 (Normal) dan layak sesuai nilai baku mutu dari Permenkes No: 492/Menkes/Per/IV/2010 adalah 6,5-8,5. Kandungan $\mathrm{pH}$ dari keempat air sumur tidak melebihi nilai baku mutu maksimum. Air sebaiknya netral, tidak asam atau basa, untuk mencegah terjadinya pelarutan logam berat dan korosi jaringan distribusi air. Air adalah bahan pelarut yang baik maka dibantu dengan $\mathrm{pH}$ yang tidak netral dapat melarutkan berbagai elemen kimia yang dilaluinya (Soemirat J, 2003).

\section{c. Parameter Mikrobiologi}

Hasil analisis parameter mikrobiologi air sumur di Kefamenanu dari empat titik yang diteliti dapat dilihat pada Tabel 8. Bakteri coliform total dalam air mengindikasikan bahwa air tersebut telah tercemar oleh kotoran manusia atau hewan yang dapat menyebabkan penyakit-penyakit saluran pencernaan. Kandungan total bakteri coliform keempat sampel air sumur di Kefamenanu 2 sampel melebihi batas maksimum standar baku mutu untuk air bersih sebesar 50 per $100 \mathrm{ml}$ yaitu air sumur area Rumah Sakit >1898 coliform dan air sumur area Tulip sebesar 438 total coliform hal ini di karenakan air sumur pada area Rumah Sakit dan area Tulip sangat berdekatan dengan sumber pencemaran yaitu pada air sumur yang berdekatan dengan rumah sakit sumber pencemarannya berasal dari pembuangan limbah rumah sakit dan banyak kamar mandi (WC) masyarakat yang berdekatan dengan air sumur sehingga air dari kamar mandi tersebut akan merembes masuk kedalam tanah. Sedangkan sumber pencemaran pada air sumur area Tulip berasal dari pembuagan limbah-limbah rumah tangga, warung-warung dan air dari selokanselokan dan kotoran- kotoran sampah yang berserahkan dekat sumur tersebut. Serta air sumur Maubeli total coliform=33 dan Sasi total coliform=13 hal berbeda dengan air sumur Rumah Sakit dan air sumur Tulip karena pada air sumurMaubelidan Sasi jauh dari sumber-sumber pencemaran. Pencemaran bakteri coliform yang paling rendah adalah air sumur Sasi yaitu=13 serta paling tinggi bakteri coliform adalah air sumur Rumah Sakit=1898. Sedangkan untuk bakteri E.coli air sumur area Rumah Sakit=1898, area Tulip= 38 Maubeli total bakteri E.coli=26 dan Sasi total bakteri E.coli=13.

\section{KESIMPULAN}

\section{Kesimpulan}

Berdasarkan hasil penelitian dan pembahasan Uji Kualitas Air Sumur di Kefamenanu Ditinjau dari segi Fisik, Kimia dan Mikrobiologi di Kabupaten Timor Tengah Utara (TTU) dapat disimpulkan bahwa:

1. Kualitas air sumur gali pada Rumah Sakit dan Tulip menunjukkan hasil kualitas air yang sedang atau tidak memenuhi standar baku mutu air minum menurut Peraturan Menteri Kesehatan No.492/ MenKes / Per/ IV / 2010. Kualitas air sumur pada Maubeli dan Sasi menunjukkan hasil kualitas air yang baik dan memenuhi standar baku mutu air menurut Peraturan Menteri Kesehatan No. 492/MenKes/Per/IV/2010.

2. Konsentrasi ambang batas dari keempat air sumur menunjukan bahwa dari segi fisika empat sumur tersebut masih memenuhi standar baku mutu kualitas air bersih Peraturan Menteri Kesehatan No. 492/ MenKes / Per/ IV /2010. Dari segi kimia yang meliputi besi, mangan, timbal dan $\mathrm{pH}$ keempat sumur tersebut hanya dari segi mangan air sumur tulip tidak memenuhi baku mutu kualitas air bersih yaitu sebesar $0,7 \mathrm{mg} / \mathrm{l}$ sedangkan parameter besi, timbal dan $\mathrm{pH}$ memenuhi standar baku mutu yang ditetapkan Peraturan Menteri Kesehatan No. 492/MenKes/Per/IV/2010. Untuk parameter mikrobiologi yang meliputi coliform dan E. coli dari keempat sumur tersebut terdapat dua sumur yang tidak memenuhi standar baku mutu 
kualitas air bersih yaitu sumur area rumah sakit yang memiliki bakteri coliform dan $E$. coli=1898 dan air sumur area tulip bakteri coliform=438 dan E. coli=38. Pada area Maubeli bakteri coliform=33 dan $E$. coli=26 dan area Sasi bakteri coliform dan E. coli=13. Pada area Maubeli dan area Sasi memenuhi standar baku mutu kualitas air bersih yang ditetapkan oleh Menteri Kesehatan No. 492/MenKes/Per/IV/2010.

\section{Saran}

Saran yang dapat disampaikan oleh peneliti dalam penelitian ini adalah sebagai berikut:

1. Bagi warga area Rumah Sakit dan area Tulip Kabupaten Timor Tengah Utara (TTU) khusunya yang berdekatan dengan air sumur area rumah sakit dan air sumur area Tulip disarankan untuk memperhatikan lokasi-lokasi tempat pembuangan sampah yang berdekatan dengan air sumur agar kebersihannya tetap terjaga untuk mengurangi bakteri coliform dan $E$. coli yang terdapat dalam air serta dapat mengurangi berbagai jenis penyakit diare, penyakit kulit seperti gatalgatal. Sebelum memanfaatkan air sumur untuk dikonsumsi terlebih dahulu seperti membuat penyaringan menggunakan pasir halus, pasir kasar, batu krikil, arang dan kain halus, karena bilaair sumur disaring terlebih dahulu dapat membuat kondisi air lebih baik

2. Bagi penduduk area Maubeli dan Sasi disarankan untuk tetap menjaga lingkungan air sumur gali agar kondisi air sumur tetap baik. Masyarakat area Maubeli dan Sasi tidak perlu khawatir untuk mengkonsumsiair sumur tersebut, karena kaulitas air sumur baik dan layak untuk dikonsumsi dan masih dibawah standar baku mutu kualitas air bersih sesuai Peraturan Menteri Kesehatan No. 492/MenKes/Per/IV/2010

3. Bagi pemerintah khususnya aparat desa maupun instansi yangterkait mengenai kebutuhan air bersih agarmemperhatikan kualitas maupun kuantitas air yang dikonsumsi oleh penduduk agar warga bisa hidup layak dan sehat dengan cara memberi bantuan penyaluran air bersih.

\section{DAFTAR RUJUKAN}

Aqnes Budiarti. 2015. Kajian kualitas air sumur sebagai sumber air minum di kelurahan gubug kecamatan gubug kabupaten grobogan.

Astuti, B. C. (2015, maret). Kualitas air sumur desa bantaran sungai bengawan solo berdasarkan aspek kemasyarakatan dan standar menteri kesehatan. Jurnal Matematika, Saint, dan Teknologi, vol 16, hal 18-25.

Azwar Ali, S. M. (2013). Kajian kualitas air dan status mutu air sungai metro di kecamatan sukun kota malang. Jurnal Bumi Lestari, No. 2, Volume 13, 265-274.

Depkes R.I. (1999). Metode Penelitian Kesehatan, Penuntun Latihan Metode Penelitian. Jakarta: Balai Penelitian dan Pengembangan Kesehatan, Gramedia Printing Group.

Endar Budi Sasongko, E. W.2014. Kajian kualitas air dan penggunaan sumur gali oleh masyarakat disekitar sungai kaliyasa kabupaten cilacap.vol 12 hal 72-78.Cilacap.

Handoyo, K. (2014). Khasiat dan keajaiban Air putih. Jakarta Timur: Dunia Sehat.

RI,D. (2010). Peraturan Menteri Kesehatan RI No 492 / Menkes/ Per/ IV/ 2010 tentang Persyaratan Kualitas Air Minum. Jakarta.

Soemirat,J.(2003). Toksikologi Lingkungan. Yogyakarta: Gadjah Mada University Press.

Sudadi, P. (2003). Penentuan kualitas air tanah melalui analisis unsur kimia terpilih. Buletin Geologi Tata Lingkungan, 13(2), September 2003, 81-89. 
Waluyo, L.(2014). Mikrobiologi Umum. UMM Press, Malang. Hal. 109, 134 , 132,142 152,175176.

Wardhana, W. (2001). Dampak Pencemaran Lingkungan. Penerbit Andi offset: Yogyakarta Warlina. (2004). Pencemaran Air.Institut Pertanian Bogor.

WHO.(2002). Segalanya Tentang Air. http: //www. WorldHealthOrganizatio .com / Diakses pada tanggal 5 Januari 2015.

Yusnidar Yusuf, F. N. (2011). Analisa kandungan air sumur warga rt12, 17 dan 18 rw 09 kelurahan kelapa dua wetan kecamatan ciracas: Jakarta Timur. 